\title{
In-service Piping Inspection Work-aid Tool for Oil \& Gas Industries
}

\author{
J.C. Lee ${ }^{1}$, H. A. Aziz ${ }^{1,{ }^{*} H .}$ Osman ${ }^{1}$, L.S. Tan² and N. A. Manaf ${ }^{2}$ \\ ${ }^{1}$ Faculty of Industrial Science and Technology, Universiti Malaysia Pahang, 26600 Pahang, Malaysia. \\ 2Malaysia-Japan International Institute of Technology (MJIIT), Universiti Teknologi Malaysia, 54100 Kuala Lumpur, Malaysia
}

\begin{abstract}
Piping systems are important in the oil and gas plant's operation, but continuous damage is harming the piping system due to extensive usage resulting in the increase of accident cases. API 570 Piping Inspection Code: In-service Inspection, Rating, Repair, and Alteration of Piping Systems has proposed an in-service piping inspection practice to ensure the in-service piping is functionable by identifying the remaining life of the piping system. However, the in-service piping inspection process is numerous and complicated where certain steps may be skipped, and data collected may lost along the process. The in-service piping inspection framework followed by a work-aid tool is developed in this study based on API 570 to guide the user the piping inspection process along with providing a depository database for document storage. Validation test is conducted by collecting feedback from professional piping engineer using System Usability Scale followed by conducting a case study using secondary data and sample attachment to test the functionality of the work-aid tool. The work-aid tool can guide the piping inspection process and provide a systematic documentation method for corresponding inspection documents. Case study in the industry is recommended to test the usability of the tool in the industry.
\end{abstract}

ARTICLE HISTORY

Received: $16^{\text {th }}$ June 2020

Revised: $2^{\text {nd }}$ Dec 2020

Accepted: $28^{\text {th }}$ Feb 2021

\section{KEYWORDS}

In-service piping

Piping inspection,

Inspection process,

Piping inspection work-aid

\section{INTRODUCTION}

Pipeline and piping systems are considered the backbone in the plant's oil and gas industries. Extensive usage of the pipeline and piping system will lead to continuous damage towards the system as the number of accidents has increased significantly due to the increase in the number of ageing pipelines that are still in-service [1]. Continuous operation throughout the day and night of the piping system will be hindered by defects in the system, such as corrosion, weld defects and third-party damage [2]. As a result, consequences such as economic, environmental, and human losses are done due to these defects. For example, the average number of gas pipelines in the East Harlem where gas pipeline leakage and explosion occurred in 2014 is 56-years old, resulting in a death toll of 8 persons and injured at least 70 persons [3]. Meanwhile, the pipeline accident at Qingdao, People's Republic of China, cost approximately 100 million US dollars direct financial loss and 62 fatalities and 136 injuries [4]. Kaohsiung pipeline gas explosion in 2014 that took place at a busy road has resulted in a total of 32 deaths and 321 injuries [5]. Other than these accidents, a study also concluded that a total of 4,239 fatalities are recorded based on 23 oil and gas pipelines fatal accidents studied in the research [6].

Regular monitoring and in-service analysis are required to be conducted from time to time to ensure the piping system's sustainability [7]. Research has been conducted in the oil and gas industries to discuss the inspection techniques and methods for pipeline and piping system's physical condition along with corrosion prediction models [8]. Various inspection concepts, tools, methods, and recommended practices are also introduced to improve the piping system integrity measuring process. For example, a piping inspection and maintenance protocol is developed to improve the piping inspection program by simulating and visualising the piping system assessment [9]. Risk-based Inspection (RBI) is one of the widely used inspection concepts based on a degradation mechanism where numerous software and systems have been developed to promote the application of this concept in the piping inspection program as risk is taken into consideration plan the inspection interval [10].

Even with all the introduced concepts, tools, methods and recommended practices, the inspection of in-service piping in the oil and gas industry is still a complicated process as numerous elements are required to be well inspected and analysed before planning the further action to be taken. Each step in the inspection process plays a significant role as data and reports will be generated as an input influencing the decision to set the inspection interval. However, due to the numerous and complicated inspection process, a large amount of data and reports will be generated as evidence of conducting the inspection and may be lost when proper documentation is absent. Certain inspection may also skip by the inspector due to fatigue and stress caused by the heavy workload along the inspection process. As a result, corrosion and other damage mechanisms present within the piping system may not be identified correctly, leading to accident. Therefore, this study aims to present a framework and a developed work-aid tool in a form of database model to guide the user while inspecting the in-service oil and gas piping. This work is based on API 570 and provides them a data depository platform to keep all the data and reports generated from the inspection. 


\section{METHODOLOGY}

Figure 1 illustrates the process study flow in this study. The in-service piping inspection framework is developed based on API 570 Piping Inspection Code: In-service Inspection, Rating, Repair, and Alteration of Piping Systems, where fundamental inspection processes are outlined to guide the process of developing the work-aid tool. The developed framework consists of five main parts: inspection plan, piping preparation, piping inspection, corrosion rate and remaining life, and inspection interval. The requirements stated by the API 570 inspection code for each of the five main parts are identified and included later in the work-aid tool to determine the compliance process's compliance towards the code. Data documentation is also included in the framework as a key element to provide synchronised inspection data management.

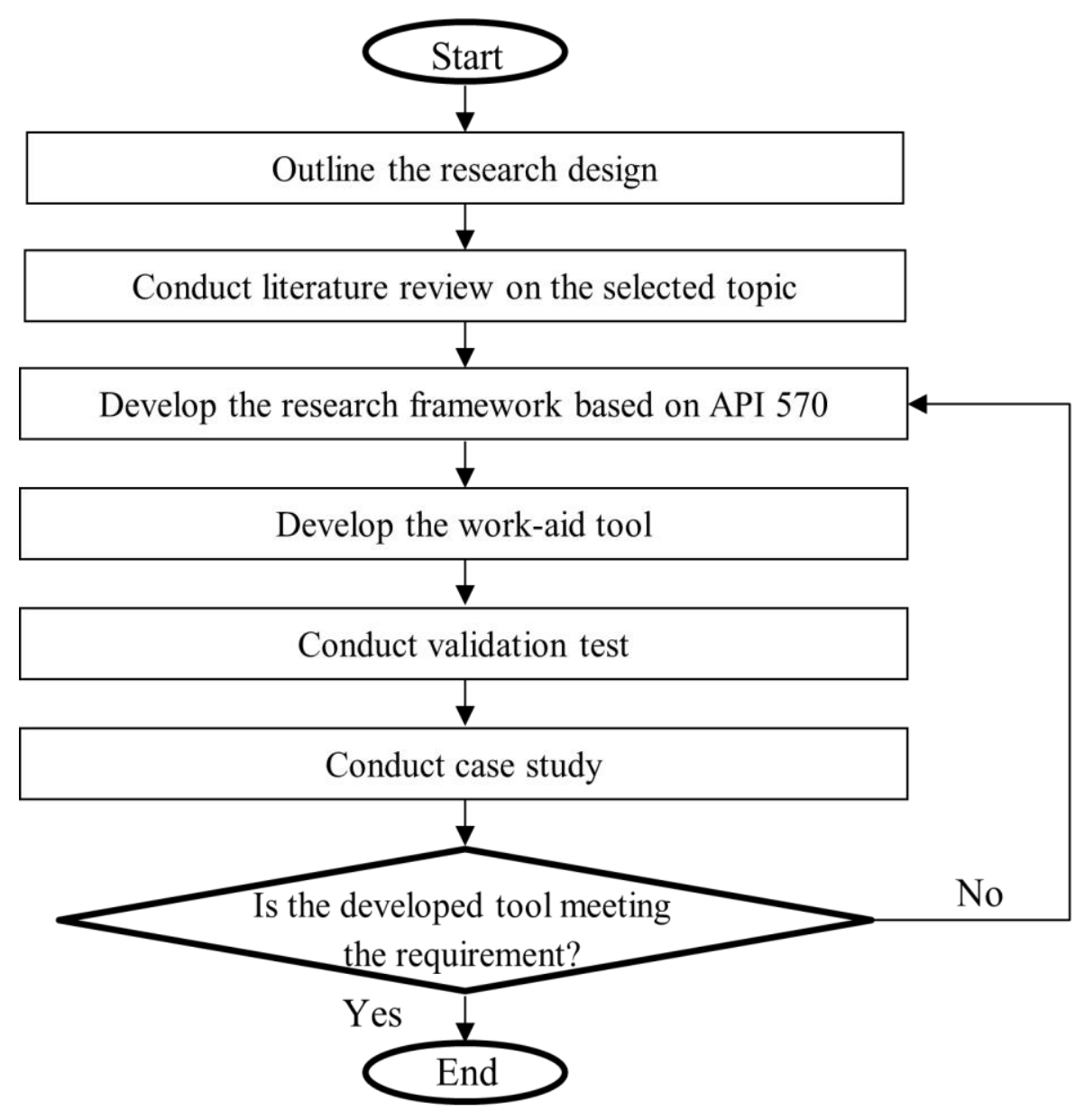

Figure 1. The process study flow

\section{Work-aid Tool}

The in-service piping inspection framework developed in this study is implemented through the work-aid tool. The work-aid tool is developed using Microsoft Access, where the main interface is created using "Modal Dialog Form" to provide a platform to link the work-aid tool and report preview. The five main parts of the framework are demonstrated in five interfaces created using "Form" where each form is linked to the corresponding back end "Table" for data storage. These interfaces are arranged in the same order of the inspection process, starting from preparing the inspection plan until the next inspection date is set based on the identified inspection interval. As stated in API 570, each inspection process's requirements are listed in the respective interface to improve compliance towards the guideline. The fourth interface which is the corrosion rate and remaining life interface is developed using "Calculated Field" where corrosion rate and remaining life of the piping system is calculated automatically by the work-aid tool based on the data input such as piping thickness and time difference between the inspection by the user.

The external storage location such as Google Drive link where inspection plans and reports are kept can be recorded in the work-aid tool and attachment such as pictures, reports, and supporting documents can be attached to act as evidence for completing the task stated in the tool. Meanwhile, the in-service piping inspection's incomplete task can be identified through the checkbox provided in the work-aid tool. 


\section{Validation test and case study}

The work-aid tool is validated by a professional piping engineer who has involved in the in-service piping inspection through System Usability Scale (SUS) where a SUS score can be calculated. Scores are assigned for the feedback ranging from 1 to 5 in the sequence of strongly disagree, disagree, neutral, agree and strongly agree. The score is calculated separately for both odd-numbered (X) and even-numbered (Y) questions. X is obtained by subtracting 5 from the total score for all the odd-numbered question,

$$
X=\sum \text { Score of odd number question }-5
$$

and $\mathrm{Y}$ is calculated by subtracting the total score of all even-numbered question from 25 ,

$$
Y=25-\sum \text { Score of even number question }
$$

Lastly, both $\mathrm{X}$ and $\mathrm{Y}$ are added up to obtain $\mathrm{Z}$, which is then multiplied by 2.5 to get the SUS score.

$$
\begin{gathered}
Z=X+Y \\
\text { SUS score }=Z \times 2.5
\end{gathered}
$$

Based on the obtained score (Z), a major improvement on the work-aid tool is conducted when the score is below 68 , the SUS score average, while the minor configuration is conducted for the score achieved above 68.

Case study using secondary data and sample attachment is conducted after the tool is developed and validated to illustrate and test the work-aid tool's operation. The secondary data include the data in the previous inspection report obtained from online open sources, such as inspector name, type of inspection conducted, inspection findings, and piping systems' thickness. The work-aid tool is tested its functionality by identifying the ability to capture and store the data and sample attachment in the back-end database. Other than that, the automated corrosion rate and remaining life calculation in the work-aid tool is tested using the piping thickness and time difference recorded in the report.

\section{RESULTS AND DISCUSSION}

\section{In-service Piping Inspection Framework}

Figure 2 illustrate the in-service piping inspection framework developed in this study. The framework commences by checking the previous inspection date and determine the needs of a new inspection in the piping system. The process will be ended when the new inspection is not required to be conducted. Meanwhile, an inspection that has been found necessary to be conducted requires an inspection plan. A new inspection plan needs to be developed when the previous inspection plan is not available for the inspection process. The previous inspection plan can be used when there are no new variables or changes installed in the piping system. Amendment on the last plan inspection is required based on the new variables and introduced modifications to the piping system.

After developing the new inspection plan or making amendments on the previous inspection plan, the inspection plan needs to be checked to ensure it meets the requirement as specified in API 570. An inspection plan that did not meet the requirement shall be revised and later reverified by an authorised person. The process continues by reviewing the inspection supporting documents where absent documents need to be prepared, including previous record, piping inspection procedure, non-destructive testing profile, and emergency response plan. The user shall ready the piping for inspection to ensure the inspection process's smoothness, such as piping isolation, blinds installation, leak testing, and leak investigation.

Piping inspection is then conducted to collect results and document the result for future usage. API 570 has stated several inspection types such as internal visual inspection, valves inspection, corrosion under insulation inspection and vibrating piping inspection. The documented result shall be kept safely to be used in the analysation stage. The corrosion rate and remaining life can be calculated based on the data obtained from the inspection. The final step of the piping inspection is setting the upcoming inspection date based on the data analysed. The final decision on the inspection interval shall be documented as a reference to support the planning on the upcoming inspection. 


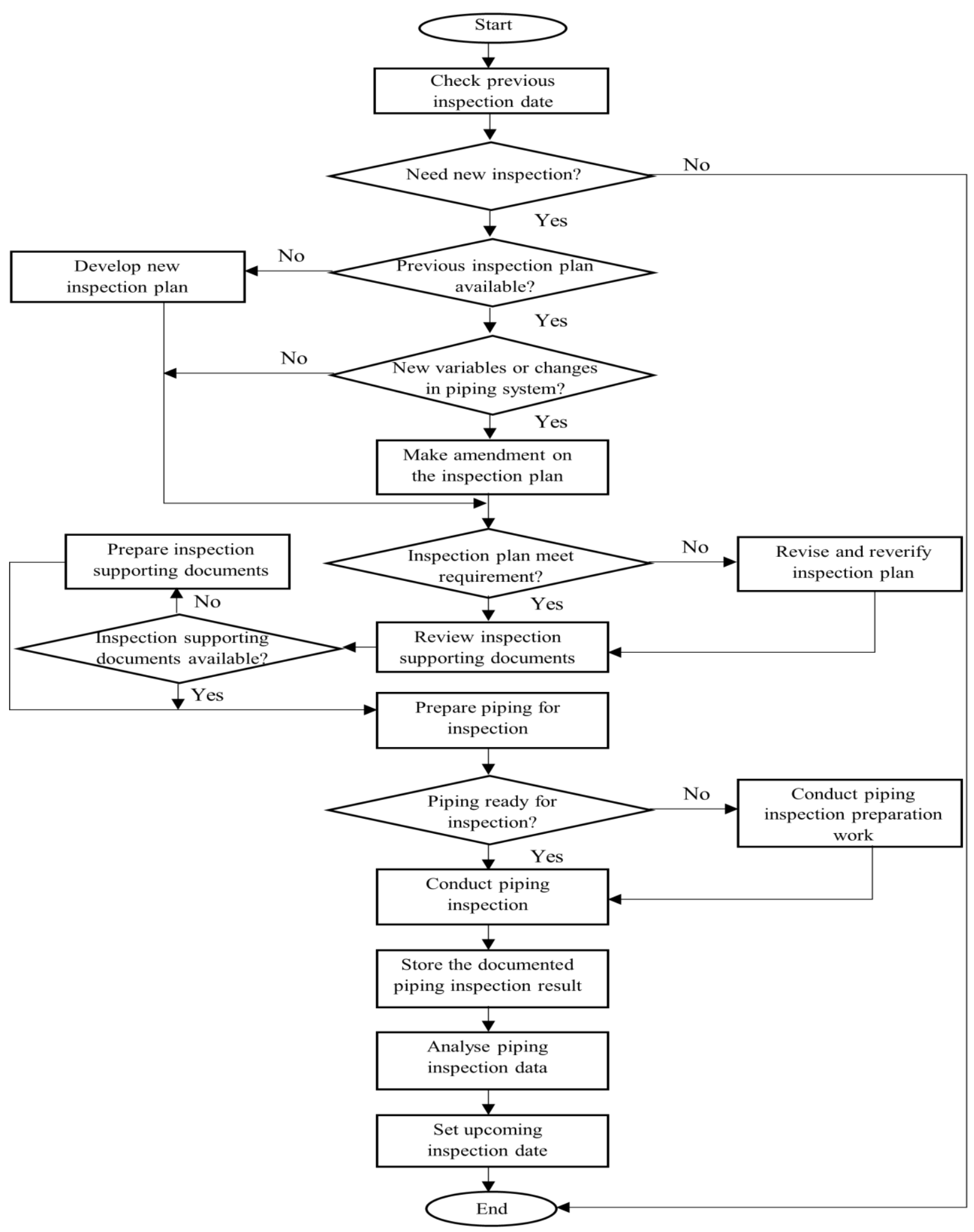

Figure 2. In-service piping inspection framework

\section{In-service Piping Inspection Work-aid Tool for Oil \& Gas Industries}

The in-service piping inspection work-aid tool for oil and gas industries consists of one pop-up window, five forms, five tables, and five reports. Figure 3 illustrate the pop-up window created using the "Modal Dialog Form". The window functions as the navigator interface that will be activated once the Microsoft Access file is opened. User can access the work-aid tool or the report through the button provided in the interface. The work-aid tool aimed to guide the user on the in-service piping inspection process and function as a depository database to allow the deposit of inspection-related 
documents and items to act as evidence to prove the completion of a process. Evidence can be attached in the tool directly or stored at external sources in the attached hyperlink.

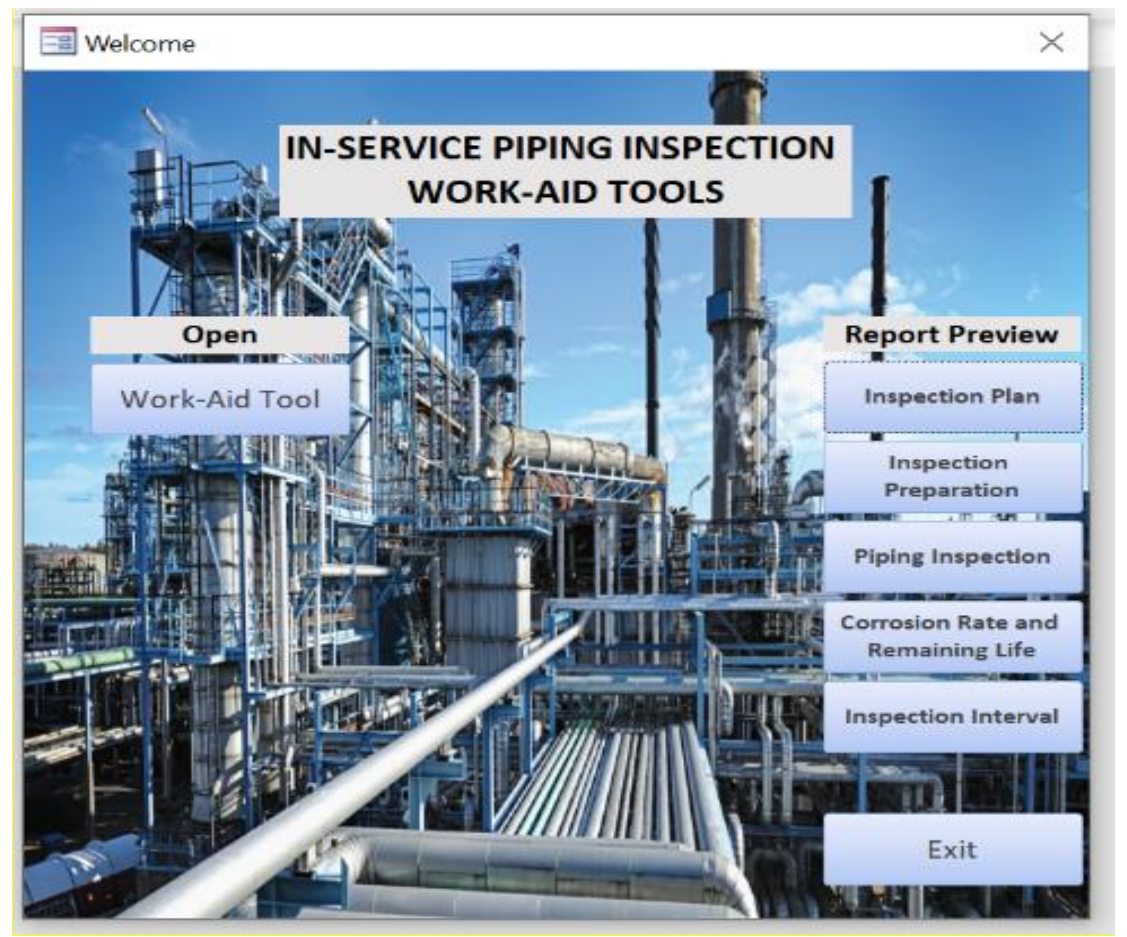

Figure 3. Pop-up window upon activation of the Microsoft Access file

Compliancy of the inspection process can be easily identified through the check box provided within the user interface as the ticked check box shows that the process is completed. Other than that, the piping system's corrosion rate and remaining life can be calculated automatically by the work-aid tool based on the formula stated in API 570, where data required for the calculation need to be inserted manually. Lastly, the identified inspection interval can be recorded in the inspection interval interface, along with the next inspection due date.

The work-aid tool can generate a customised report based on the data input in each of the interface. User can customise the report to only include the data needed based on the purpose of the report served. For example, the user can exclude the column for the corrosion specialist's name, which is not available, rather than showing an empty column in the report. Figure 4 shows the sample report of the Inspection Plan interface. 


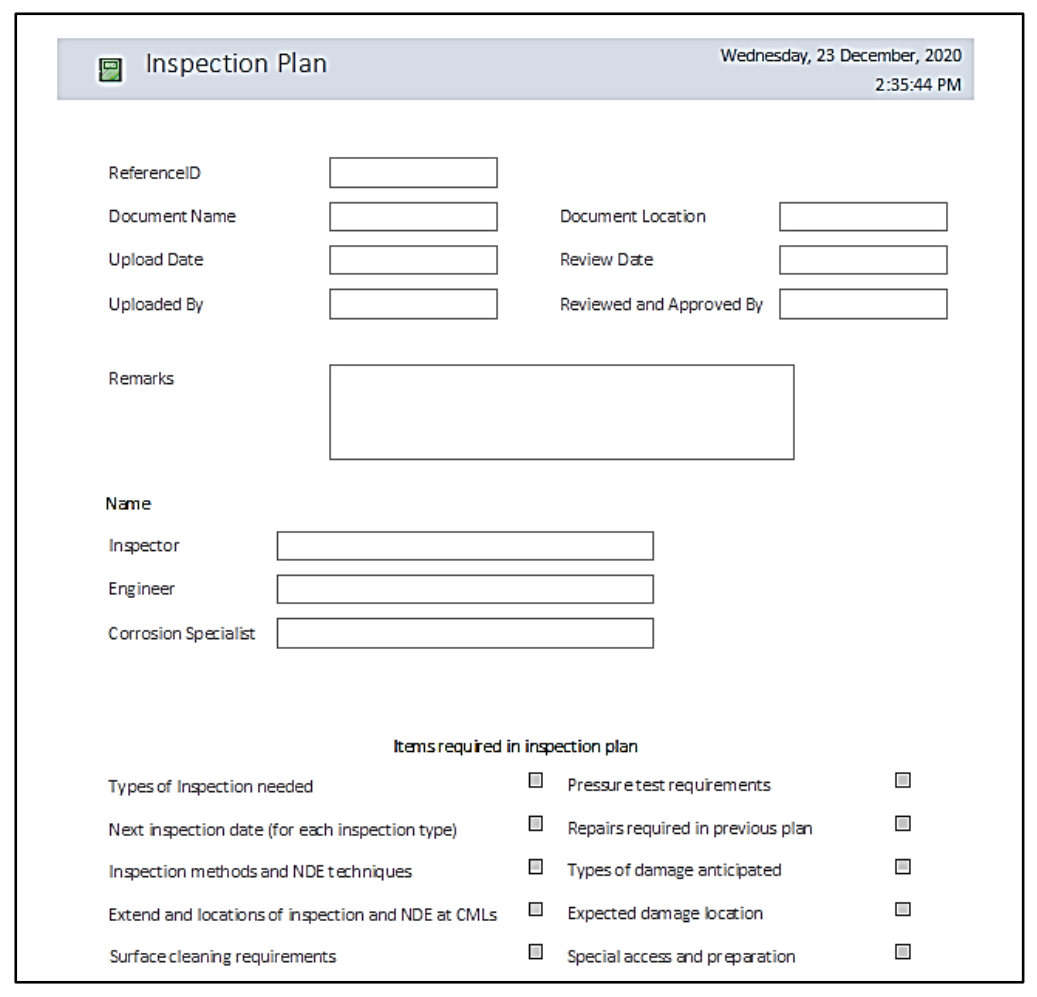

Figure 4. Sample report for Inspection Plan interface

\section{Validation and Case Study}

The work-aid tool validation is conducted by a professional piping engineer using the System Usability Scale (SUS). A SUS score of 80 is obtained using the Formula (4), and the score is above the average of 68 set by the SUS scoring. Hence only minor changes are required to improve the work-aid tool. Figure 5 shows the feedback from the piping engineer. From the feedback, the respondent agree that the work-aid tool is likely to be used frequently and it is easy to use. The work-aid tool's design is not considered complex where support from a technical person to operate the tool is unnecessary. Other than that, the respondent also agrees that the various functions in this work-aid tool are well integrated, such as the checkbox and drop-down option for the current status to identify the progress and compliance of the process towards the API 570 requirements.

Next, the work-aid tool's inconsistency is absent, and it is not cumbersome or awkward to use the work-aid tool. Respondent feel that there is not much preparation and learning process is needed before the user can get use to the operation of the work-aid tool. The respondent strongly agrees that most people will learn to use this work-aid tool very quickly and the respondent is very confident in using the work-aid tool during the inspection process as the overall design is simple, direct and user-friendly. Overall, the respondent's feedback is showing a positive response toward the work-aid tool in aiding the piping inspection process.

Meanwhile, a case study using secondary data and sample attachment is conducted to demonstrate and test the workaid tool's framework. The secondary data is obtained through online open sources, while sample attachment is developed based on the report template. These data are developed and used solely in this work-aid tool for demonstration purposes. Based on the case study conducted, the work-aid tool can capture the user's data input, including the details for each specification and external storage address hyperlink of the documents stored in Google Drive. Other attachments such as pictures and document file are stored in the database and can be easily accessed without any issue. The calculation of the corrosion rate and remaining life of the piping system is performed automatically by the work-aid tool based on the data inserted at the interface. A report for each interface can be generated to present the information in an orderly manner. 


\begin{tabular}{|c|c|c|c|c|c|}
\hline System Usability Scale & 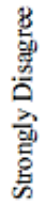 & 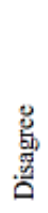 & $\begin{array}{l}\overline{\text { J }} \\
\text { 岂 }\end{array}$ & 萨 & 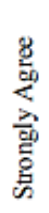 \\
\hline 1. I think that I would like to use this work-aid tool frequently. & $\square$ & $\square$ & $\square$ & $\otimes$ & $\square$ \\
\hline 2. I found the work-aid tool unnecessarily complex. & $\square$ & $\otimes$ & $\square$ & $\square$ & $\square$ \\
\hline 3. I thought the work-aid tool was easy to use. & $\square$ & $\square$ & $\square$ & $\otimes$ & $\square$ \\
\hline $\begin{array}{l}\text { 4. I think that I would need the support of a technical person to } \\
\text { be able to use this work-aid tool. }\end{array}$ & $\square$ & $\otimes$ & $\square$ & $\square$ & $\square$ \\
\hline $\begin{array}{l}\text { 5. I found the various functions in this work-aid tool were well } \\
\text { integrated. }\end{array}$ & $\square$ & $\square$ & $\square$ & $\otimes$ & $\square$ \\
\hline $\begin{array}{l}\text { 6. I thought there were too much inconsistency in this work- } \\
\text { aid tool. }\end{array}$ & $\square$ & $\otimes$ & $\square$ & $\square$ & $\square$ \\
\hline $\begin{array}{l}\text { 7. I would imagine that most people would learn to use this } \\
\text { work-aid tool very quickly. }\end{array}$ & $\square$ & $\square$ & $\square$ & $\square$ & $\otimes$ \\
\hline $\begin{array}{l}\text { 8. I found the work-aid tool very cumbersome/ awkward to } \\
\text { use. }\end{array}$ & $\square$ & $\otimes$ & $\square$ & $\square$ & $\square$ \\
\hline 9. I felt very confident using the work-aid tool. & $\square$ & $\square$ & $\square$ & $\square$ & $\otimes$ \\
\hline $\begin{array}{l}\text { 10. I needed to learn a lot of things before I could get going } \\
\text { with this work-aid tool. }\end{array}$ & $\square$ & $\otimes$ & $\square$ & $\square$ & $\square$ \\
\hline
\end{tabular}

Figure 5. Feedback from piping engineer

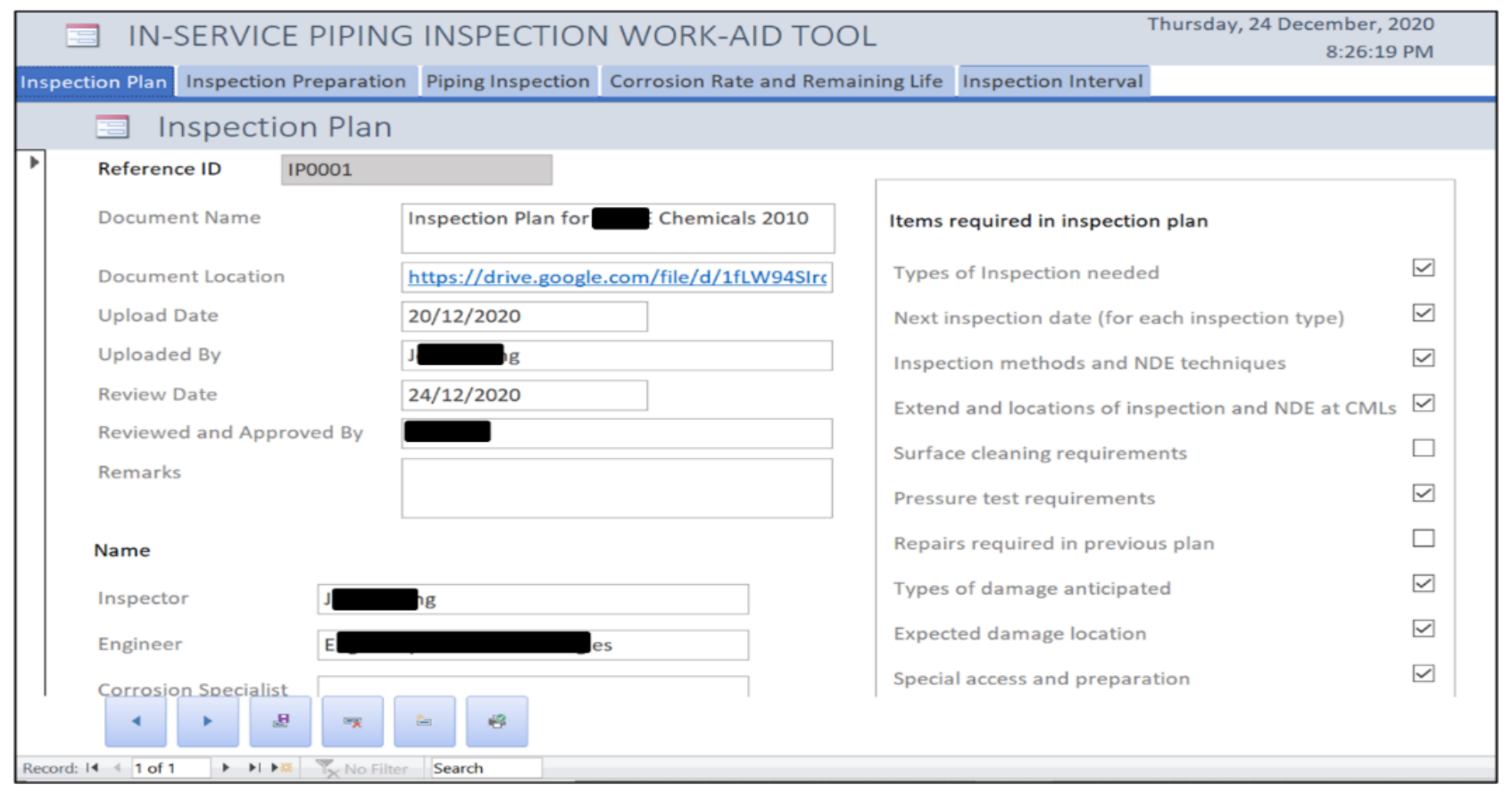

Figure 6. Inspection Plan interface 
Figure 6 shows the inspection plan interface in the work-aid tool. The Reference ID will be generated by the tool. This interface allows user to key in detail related to the inspection plan attached to the tool such as document name, upload date, and person-in-charge who uploaded the inspection plan. The location where the inspection plan is stored externally can be recorded in the work-aid tool, where the user can open the inspection plan through the hyperlink. The checkbox as shown in Figure 7 illustrated the items required in the inspection plan, as stated in API 570. In this case, surface cleaning and repairs from the previous inspection were not completed.

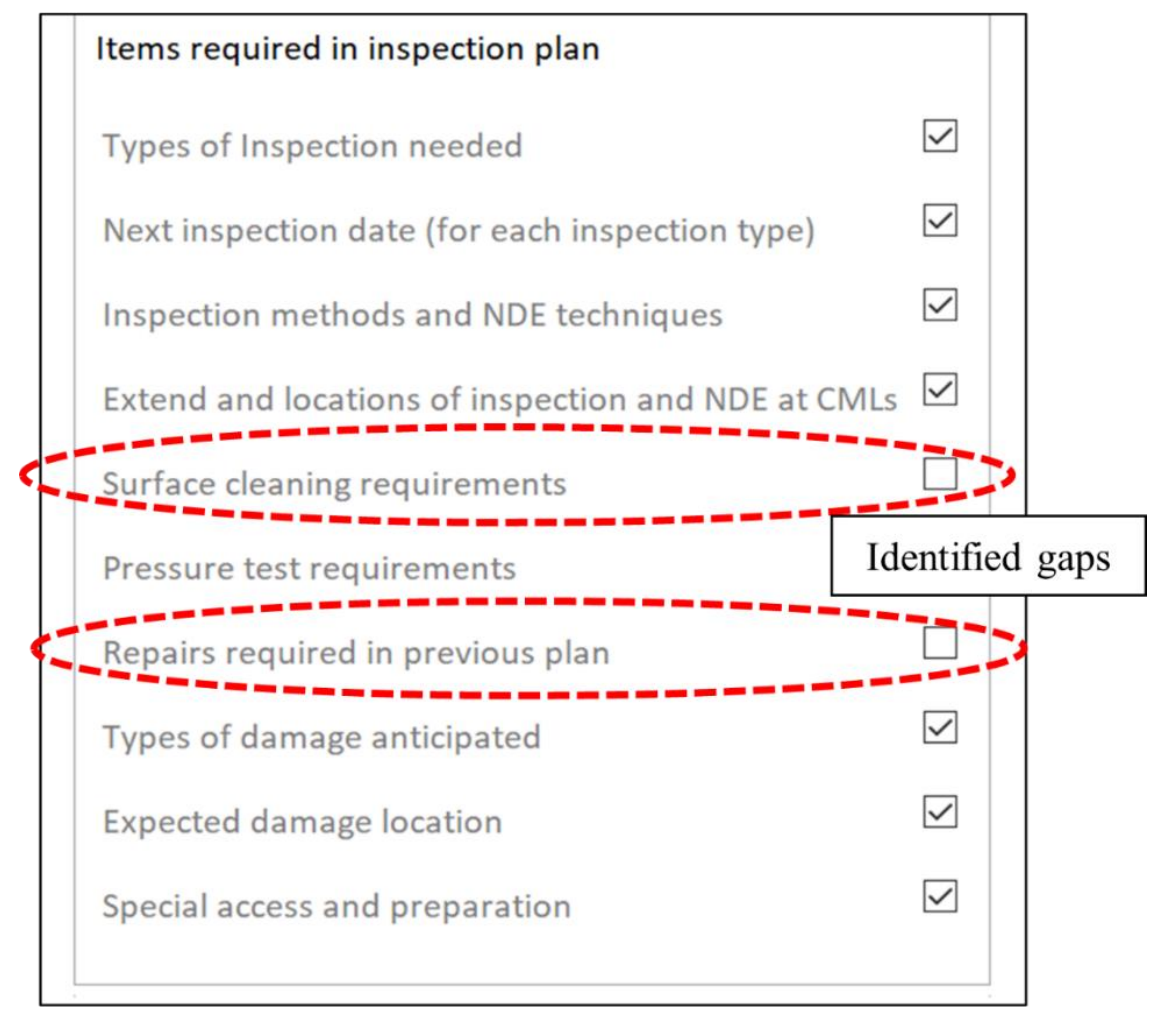

Figure 7. Items required in inspection plan

The second interface, which is the inspection preparation interface, is shown in Figure 8. This interface is divided into two categories, which are document preparation and piping preparation. The four documents need to be reviewed in this interface, where the user can fill up the document name and document location. Upon completion, the checkbox can be ticked to represent the documents are complete and available for the inspection process, and the action taker can give any remarks on the document. In this case study, the field for profile RT or UT NDE is left blank, indicating the absence of this document where actions can be taken to prepare this document for the inspection process. 


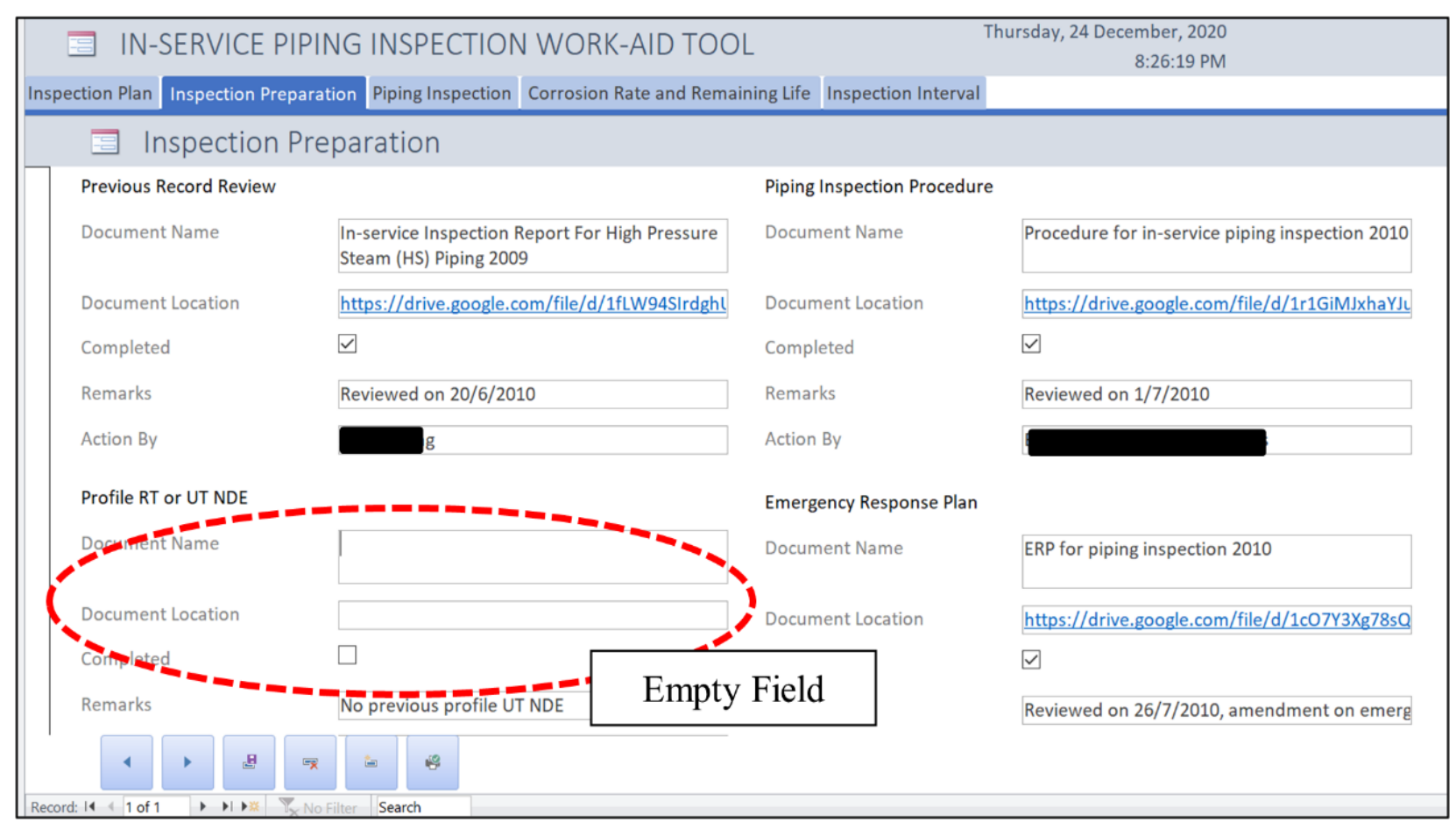

Figure 8. Inspection Preparation interface (document preparation)

Meanwhile, Figure 9 is showing the piping preparation requirements before the piping inspection can commence. A drop-down input option can be chosen where it best fit the status of the required preparation work. Evidence can be attached along in the field corresponding to each requirement. Pictures, report, and any other suitable evidence can be attached to support the decision made on the status of each requirement.

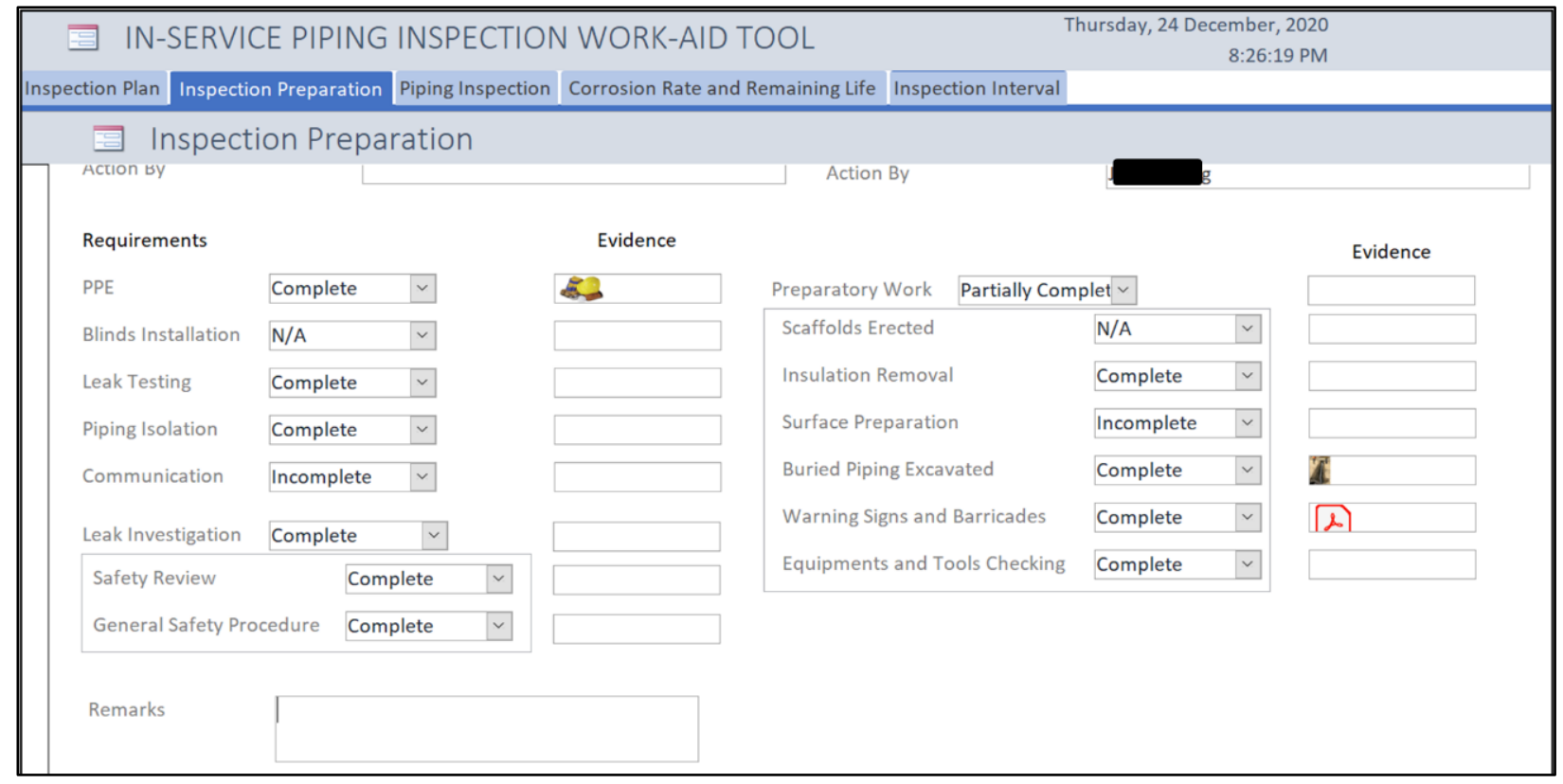

Figure 9. Inspection Preparation interface (piping preparation)

The piping inspection interface is shown in Figure 10. In the Piping Inspection interface, the Reference ID needs to be filled by user based on the ID in the previous interface as multiple inspection reports may be attached to the same inspection process. The type of inspection can be chosen from the list developed based on API 570, as shown in Figure 11. The inspection date, report name and location, remarks and name of action taker shall be filled in. The checkbox is selected to indicate the completion of attaching the corresponding inspection report into the work-aid tool. 


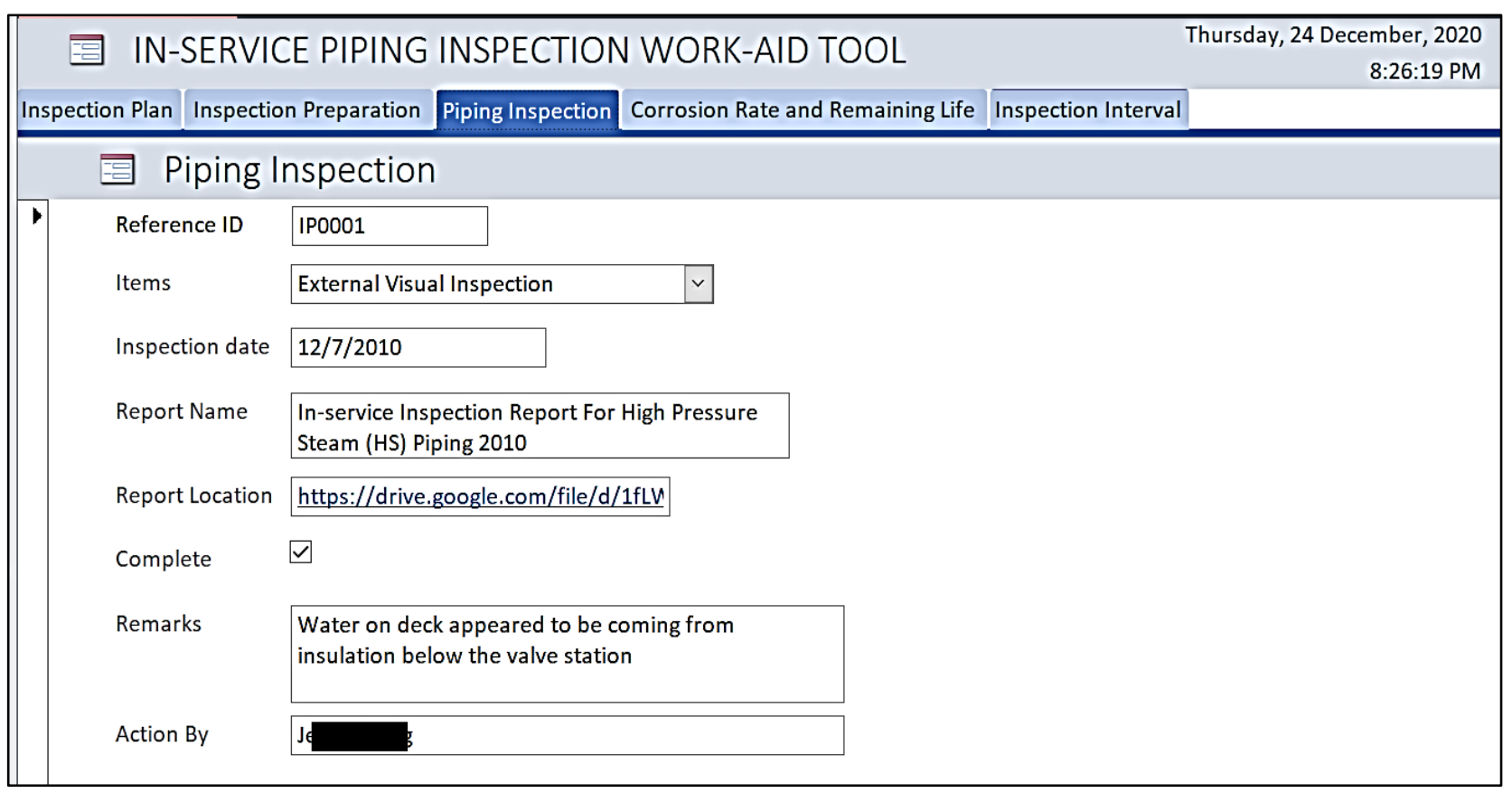

Figure 10. Piping Inspection interface

\begin{tabular}{|c|c|c|}
\hline Items & & $\sim$ \\
\hline Inspection date & $\begin{array}{l}\text { Internal Visual Inspection } \\
\text { On-stream Inspection } \\
\text { Thickness Measurement Inspection }\end{array}$ & \\
\hline Report Name & $\begin{array}{l}\text { External Visual Inspection } \\
\text { Vibrating Piping Inspection }\end{array}$ & \\
\hline Report Location & $\begin{array}{l}\text { Supplemental Inspection } \\
\text { Condition Monitoring }\end{array}$ & \\
\hline Complete & $\begin{array}{l}\text { Corrosion Under Insulation Inspection } \\
\text { Mixing Point Inspection }\end{array}$ & \\
\hline Remarks & $\begin{array}{l}\text { Injection Point Inspection } \\
\text { Pressure Testing } \\
\text { Material Verification and Traceability } \\
\text { Valves Inspection }\end{array}$ & \\
\hline Action By & $\begin{array}{l}\text { Welds In-service Inspection } \\
\text { Flanged Joints Inspection }\end{array}$ & \\
\hline
\end{tabular}

Figure 11. Types of Inspection based on API 570

Figure 12 illustrate the corrosion rate and remaining life interface. In this study, the piping system's corrosion rate and remaining life can be calculated automatically using the Corrosion Rate and Remaining Life interface by providing the work-aid tool the piping thickness, time difference between the two measured thickness and the required thickness of the piping system. The result is calculated based on the formula stated in API 570. Due to the lack of previous UT measurement reading, the piping thickness for short-term corrosion rate is assigned by the author based on the initial thickness of the piping system to demonstrate the work-aid tool's function. The short-term corrosion rate and remaining life of the piping system obtained in this simulation is $0.08 \mathrm{~mm} /$ year and 54.53 years, while the long-term corrosion rate and remaining life of the piping system is $0.07 \mathrm{~mm} /$ year and 62.92 years remain. The time taken to calculate the corrosion rate and remaining life of the piping system by using the work-aid tool is less than the time needed to do the calculation manually. Other than that, the results are stored in the database based on the Reference ID, where the user can easily refer to the data when it is needed to plan for the next inspection interval. 


\begin{tabular}{|c|c|c|c|c|}
\hline & ction Plan Inspection Preparation Piping Inspection & \multicolumn{3}{|c|}{ Corrosion Rate and Remaining Life Inspection Interval } \\
\hline \multicolumn{5}{|c|}{ Corrosion Rate and Remaining Life Calculator } \\
\hline \multirow[t]{9}{*}{ 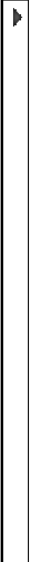 } & Reference ID IP0001 & & & \\
\hline & SHORT TERM CORROSION RATE & & LONG TERM CORROSION RATE & \\
\hline & Previous Thickness & $7.87 \mathrm{~mm}$ & Initial Thickness & $10.97 \mathrm{~mm}$ \\
\hline & Actual Thickness & $7.72 \mathrm{~mm}$ & Actual Thickness & $7.72 \mathrm{~mm}$ \\
\hline & Time (years) between Previous and Actual Thickness & 2.00 year & Time (years) between Initial and Actual Thickness & 50.00 year \\
\hline & Corrosion rate & $.08 \mathrm{~mm} /$ year & Corrosion rate & $.07 \mathrm{~mm} /$ year \\
\hline & SHORT TERM REMAINING LIFE & & LONG TERM REMAINING LIFE & \\
\hline & Required Thickness & $3.63 \mathrm{~mm}$ & Required Thickness & $3.63 \mathrm{~mm}$ \\
\hline & Remaining Life & 54.53 year & Remaining Life & 62.92 year \\
\hline
\end{tabular}

Figure 12. Corrosion Rate and Remaining Life interface

The inspection interval interface is shown in Figure 13. The Reference ID needs to be filled by the user using the same ID as the Piping Inspection interface. The "Description" field is used to fill up the type of inspection conducted in accordance with the Piping Inspection interface. The inspection date is recorded in the work-aid tool, followed by assigning the suitable inspection interval towards the inspection.

\begin{tabular}{|c|c|c|}
\hline & Inspection I & nterval \\
\hline \multirow[t]{7}{*}{1} & Reference ID & IP0001 \\
\hline & Date & $24 / 12 / 2020$ \\
\hline & Description & External Visual Inspection \\
\hline & Remarks & $\begin{array}{l}\text { Strip insulation from valve station and } \\
\text { check for possible steam leak }\end{array}$ \\
\hline & Latest Inspection Date & $12 / 7 / 2010$ \\
\hline & Inspection Interval & 60 month(s) \\
\hline & Next Inspection Before & $13 / 7 / 2015$ \\
\hline
\end{tabular}

Figure 13. Inspection Interval interface

\section{CONCLUSION}

This study developed the framework to ease in-service piping inspection and demonstrated using the work-aid tool. The in-service piping inspection work-aid tool can guide the inspection process for in-service piping and used for documentation of inspection data. The validation using SUS by piping engineer and the case study is conducted to validate both the framework and work-aid tool as they meet its expectation in guiding the process of in-service piping inspection. The framework and work-aid tool to guide the in-service piping inspection based on API 570 and identifying the incompliance of the process towards the code. The work-aid tool can eventually serve as a guideline, a depository database, auditing tool for in-service piping inspection. The author recommends conducting an actual case study in the industry to obtain primary data to test the work-aid tool's functionality. The actual case study can identify the tool's suitability to meet the industry's expectation and actual implementation. 


\section{ACKNOWLEDGEMENT}

The authors would like to acknowledge the Faculty of Industrial Science and Technology, Universiti Malaysia Pahang, to provide the platform to conduct this study and the piping engineer who assist in validating the developed tool. The author would like to acknowledge Collaborative Research Grant National (PY/2020/03416) and University Malaysia Pahang www.ump.edu.my (RDU192320) for the financial support and resources provided, also the information from companies and practitioners to make this study feasible.

\section{REFERENCES}

[1] N. M. Noor, N. A. N. Ozman, and N. Yahaya, "Deterministic prediction of corroding pipeline remaining strength in marine environment using DNV RP -F101 (Part A)," J. Sustain. Sci. Manag., vol. 6, no. 1, pp. 69-78, 2011.

[2] H. Lu, T. Iseley, S. Behbahani, and L. Fu, "Leakage detection techniques for oil and gas pipelines: State-of-the-art," Tunn. Undergr. Sp. Technol., vol. 98, no. September 2019, 2020, doi: 10.1016/j.tust.2019.103249.

[3] K. Wang, T. Shi, Y. He, M. Li, and X. Qian, "Case analysis and CFD numerical study on gas explosion and damage processing caused by aging urban subsurface pipeline failures," Eng. Fail. Anal., vol. 97, no. 1550, pp. 201-219, 2019, doi: 10.1016/j.engfailanal.2019.01.052.

[4] Y. Gong and Y. Li, "STAMP-based causal analysis of China-Donghuang oil transportation pipeline leakage and explosion accident," J. Loss Prev. Process Ind., vol. 56, no. October, pp. 402-413, 2018, doi: 10.1016/j.jlp.2018.10.001.

[5] F. Li, W. Wang, J. Xu, S. Dubljevic, F. Khan, and J. Yi, "A CAST-based causal analysis of the catastrophic underground pipeline gas explosion in Taiwan," Eng. Fail. Anal., vol. 108, no. November 2019, p. 104343, 2020, doi: 10.1016/j.engfailanal.2019.104343.

[6] M. V. Biezma, M. A. Andrés, D. Agudo, and E. Briz, "Most fatal oil \& gas pipeline accidents through history: A lessons learned approach," Eng. Fail. Anal., vol. 110, no. February, pp. 1-14, 2020, doi: 10.1016/j.engfailanal.2020.104446.

[7] Z. C. Ong, H. C. Eng, and S. Noroozi, "Non-destructive testing and assessment of a piping system with excessive vibration and recurrence crack issue: An industrial case study," Eng. Fail. Anal., vol. 82, pp. 280-297, 2017, doi: 10.1016/j.engfailanal.2016.12.007.

[8] H. Iqbal, S. Tesfamariam, H. Haider, and R. Sadiq, "Inspection and maintenance of oil \& gas pipelines: a review of policies," Struct. Infrastruct. Eng., vol. 13, no. 6, pp. 794-815, 2017, doi: 10.1080/15732479.2016.1187632.

[9] N. Farahin and W. Pao, "Prototype of Piping Inspection and Maintenance Protocol," no. September 2012, 2016, doi: 10.13140/RG.2.2.27260.95366.

[10] M. Singh and M. Pokhrel, "A Fuzzy logic-possibilistic methodology for risk-based inspection (RBI) planning of oil and gas piping subjected to microbiologically influenced corrosion (MIC)," Int. J. Press. Vessel. Pip., vol. 159, no. November 2017, pp. 45-54, 2018, doi: 10.1016/j.ijpvp.2017.11.005. 